\title{
EVALUATING CRIME ATTRIBUTABLE TO CASINOS IN THE U.S.: A CLOSER LOOK AT GRINOLS AND MUSTARD'S “CASINOS, CRIME, AND COMMUNITY COSTS"
}

\begin{abstract}
Douglas M. Walker*广
This paper examines problems in studying the relationship between casinos and crime, with a focus on a recently published, influential study (Grinols and Mustard 2006) which concluded that casinos cause a significant amount of county-level crime in the U.S. Five key issues are examined. First, the most serious problem with their analysis is that it uses a crime rate that excludes the visiting population at risk, thereby overstating the crime rate in casino counties. Second, the crime data used are potentially inaccurate. Third, the results may suffer from a bias caused by counties self-selecting into the "casino county" category. Fourth, the dummy variables used to account for casinos do not allow the authors to isolate the crime effect caused by casinos. Finally, the authors make conclusions that are not supported by their data, analysis, and results. An examination of these issues is important because it will shed additional light on the debate over the effects of casinos, and provides valuable information for subsequent researchers who study the casino-crime relationship.
\end{abstract}

\section{INTRODUCTION}

Legalized gambling has become a popular form of entertainment for consumers, and as popular a fiscal policy tool of state governments. The popularity of casino gambling has spread outside the U.S., as numerous countries have adopted or are considering the adoption of casino gambling. The "economics of casino gambling" literature includes published studies about the effects of casino gambling on economic development, tax revenues, pathological gambling behavior and social costs, bankruptcy, and crime. The literature is still young and growing, with contributions to the literature coming from researchers in a variety of academic disciplines. ${ }^{1}$

"Casinos, Crime, and Community Costs," by Earl Grinols and David Mustard, published in the Review of Economics and Statistics (February 2006, 88: 28-45), is a noteworthy contribution to the gambling literature. (Hereafter the paper and its authors are referred to as "GM".) The study purports to be the most comprehensive analysis of the relationship between casino gambling and crime ever published. No other study has attempted to examine this rela-

*I am grateful to Jay Albanese, Bill Eadington, David Forrest, Mark Nichols, Don Ross, and Richard Thalheimer for helpful comments and suggestions, and especially to John Jackson and Ben Scafidi for helpful discussions on this paper. I am responsible for the content and any errors.

$\dagger$ Associate Professor of Economics, Department of Economics and Finance, College of Charleston, Charleston, SC 29401, USA; Email: WalkerD@cofc.edu 
tionship using a nationwide data set, nor has any other study examined such a lengthy time period, in any country. The authors should be commended for undertaking such an important study. Not only is the scope of their analysis impressive, but so is the importance of their subject. The economic effects of casino gambling, including the relationship between casinos and crime, is critical in local and national policy debates in the U.S. and in many other countries.

Since the GM paper was published in a refereed journal with such high academic prestige, the paper is likely to be very influential in all subsequent research on the effects of casino gambling on crime, social costs, and local economic variables. Indeed, it has generated much discussion in the press, among policymakers, on policy activist websites, and in the gambling literature. $^{2}$ It is and will likely continue to be regarded as the authoritative work on casinos and crime.

Unfortunately, the GM paper has serious errors and oversights, the effects of which may nullify the results of the paper. The problems include their measure of the crime rate, the lack of needed data, anomalies in their crime data, a poor measure of casino gambling activity, a potential sample bias, and a skewed interpretation of the empirical results. The purpose of this paper is to examine these issues by providing a detailed analysis of the GM paper. To the extent that economic research informs policymakers, laymen, and members of the press, the errors in the GM paper call for a response. ${ }^{3}$ Moreover, the fact that the effects of gambling are still largely unknown among researchers and policymakers makes academic debate critical for advancing gambling research and policy.

The thrust of the GM paper is as follows. The authors use annual countylevel data from 1977 to 1996 to analyze whether counties with casinos have a higher rate of crime than counties without casinos, all else equal. Their data set includes all 3,165 U.S. counties. The types of crime analyzed are aggravated assault, rape, robbery, murder, larceny, burglary, and auto theft (GM 2006, p. 29). The authors use dummy variables to indicate the first year a casino operated in a particular county. Dummies are also used to indicate years since the first casino in the county was opened. The authors use these dummies, among other variables, to analyze the crime rates in casino and non-casino counties.

Their empirical findings are that the crime rate falls in both casino and non-casino counties during the lengthy time period of their study. However, "crime dropped 12.0 percentage points more in non-casino counties than in casino counties" (2006, p. 30). Since crime decreased faster in non-casino than in casino counties, GM argue that this is evidence that casinos cause crime. The only type of crime studied that was not significantly higher in casino counties was murder. The analysis in the GM paper focuses on crime occurring between two years prior to and five years after casino openings. The authors find that for the first two years prior and three years after casino openings there is little or no effect of casinos on crime. However, during the fourth and fifth years after casino openings, most forms of crime begin to escalate. 
The authors use the crime estimates in the fifth year after casino opening as the basis for some of their conclusions on the effect of casinos on crime. These estimated crime effects are then used in conjunction with cost-of-crime estimates from Miller, Cohen, and Wiersema (1996) to derive estimates of the costs of crime caused by casinos: an average of $\$ 75$ per adult in casino counties per year (GM 2006, p. 41).

The remainder of this paper discusses various problems with the GM crime analysis. Section 2 discusses the factors that GM indicate may affect crime rates. The GM computation of the crime rate is analyzed in Section 3. Section 4 is a discussion of the crime data utilized by GM. Section 5 evaluates the GM casino county variable and its implications for isolating the crime caused by casinos. Several of the GM conclusions which do not appear to be justified by their results are examined in Section 6. Section 7 concludes.

\section{DETERMINANTS OF CRIME IN CASINO COUNTIES}

The GM paper posits a model of crime rates utilizing data from the FBI's Uniform Crime Reports: County-Level Detailed Arrest and Offenses Data on arrests and offenses for Index I offenses: aggravated assault, rape, robbery, murder, larceny, burglary, and auto theft (GM 2006, p. 29). GM also obtained data on several demographic variables, including income, unemployment, income maintenance transfers, retirement, population density per square mile, total county population, and population distributions by race, age, and sex (GM 2006, p. 29). They wish to explain county level crime rates as a function of these other variables and a variable (or variables) to account for the existence of casinos.

GM suggest a variety of factors that may affect crime rates in casino counties. They explain, "between 1990 and 1996, when the number of counties with casinos increased rapidly, the crime rate dropped substantially," but that most regions experienced falling crimes rates after 1991. "Therefore, it is more appropriate to compare the magnitude of the decreases between casino and non-casino counties" (GM 2006, p. 30). ${ }^{4}$

In the "theory" section of the paper, GM discuss possible explanations for how crime may be affected by the availability of casino gambling. They provide two explanations for why casinos might reduce crime (GM 2006, p. 31): increased employment and higher wages, and economic development effects. They offer five explanations for why crime might increase as a result of casinos. These include negative development effects, higher payoffs for criminal activities, problem and pathological gambling, visitor criminality, and changes in population composition (GM 2006, pp. 31-32).

In arguing that casinos may increase the payoff to committing crime, GM explain that near casinos there is "a higher concentration of cash and potential victims" (GM 2006, p. 31). This is certainly a possibility. One might expect that criminals would be more likely to be attracted to the casinos in order to 
find potential victims. Casinos may be, in effect, "hot spots" for crime. If the presence of a casino causes an increase in crime, the increase is likely explained both by an influx of "visiting" criminals, as well as some increase in "resident" criminal activity. (Visiting criminals are defined as criminals from outside the county; resident criminals are defined as criminals who live in the casino county.)

Next GM discuss problem and pathological gamblers. We will not go into detail describing what constitutes such behavioral problems. It suffices to say that a small percentage of people develop a gambling addiction that may have a negative impact on their financial health, families, careers, etc. The American Psychiatric Association (1994) estimates that approximately 1-3\% of individuals are so afflicted. ${ }^{5}$ Pathological gamblers often engage in problematic behavior. They may steal from friends, family, or strangers in order to finance continued gambling. The point is that it is reasonable to expect that an increase in the number of pathological gamblers would tend to cause an increase in the number of crimes committed in a particular area. Studies have indicated that pathological gambling prevalence rates tend to increase in areas nearer to casinos. GM cite research finding that the percentage of problem and pathological gamblers increases significantly "when the distance to the nearest casino fell from more than 250 miles to less than 50 miles" (GM 2006, p. $33)$. This would suggest that casino county residents are perhaps more likely than visitors to become pathological gamblers, since residents are always near a casino. Visitors to the casino county must actually travel in order to gamble. In any case, some casino county residents are likely to engage in criminal activities, more so to the extent they develop pathological gambling problems. Overall, we can expect that if casinos cause more crime, the increase is likely due to both visiting and resident criminals.

The third explanation for a positive relationship between casinos and crime to be discussed here is "visitor criminality" (GM 2006, p. 32). GM suggest that casino visitors are more prone to commit and be victims of crime than other tourists. They attempt to justify this claim by comparing the crime rate in Las Vegas to other popular tourist destinations, including the Mall of America (Bloomington, MN), Silver Dollar City and other attractions (Branson, MO), and Disney World (Orlando, FL). Their comparison for 1994 is summarized below in Table $1 .{ }^{6} \mathrm{GM}$ reason that if tourists in general are largely responsible for crime, then Branson, Bloomington, and Orlando should be among the most crime-ridden places in the U.S. (GM 2006, p. 32). GM also compare crime rates at national parks to Las Vegas crime rates (GM 2006, p. 34; also see their note 13). Their findings indicate that visitor-adjusted crime rates are higher in Las Vegas than at national parks and other major tourist venues.

Their discussion would appear on the surface to provide fairly solid evidence that casinos attract tourists that are more likely than average to commit crimes. However, there are three major problems with drawing this conclusion. First, as explained by Betsinger (2005, pp. 18-19), 
EVALUATING CRIME ATTRIBUTABLE TO CASINOS IN THE U.S.

TABLE 1

Comparison of Crime Rates in Different Tourist Cities in the U.S., 1994

\begin{tabular}{lcccc}
\hline City & $\begin{array}{c}\text { Bloomington, } \\
\text { Variable }\end{array}$ & $\begin{array}{c}\text { Branson, } \\
\text { MO }\end{array}$ & $\begin{array}{c}\text { Orlando, } \\
\text { FL }\end{array}$ & $\begin{array}{c}\text { Las Vegas, } \\
\text { NV }\end{array}$ \\
\hline Visitors & 38 million & 5.6 million & 34 million & 30 million \\
Visitors per resident & 436 & 1345 & 188 & 40 \\
\# crimes per 100,000 & 11.9 & 16.4 & 64 & 187.3 \\
visitors \& residents & & & & \\
\hline
\end{tabular}

Source: Author's presentation of data from GM, p. 32.

This argument ignores the points laid out by routine activities theory. ${ }^{7}$ It is doubtful that visitors to a national park or to an historical monument present the same type of criminal opportunity as do visitors to a gambling venue; large amounts of often openly displayed cash and widely available alcohol do not usually factor into visits to locations run by the National Park Service.

Second, such comparisons take no account of the visitors' ages. Visitors to casinos in the U.S. must be at least 21 years old. (That is, the minimum age to gamble in casinos is 21.) There are no age limits at malls, at Disney World, or at Silver Dollar City in Branson. In fact, these tourist areas, as well as many of the National Park areas examined by GM, cater to children. ${ }^{8}$

We would expect the crime incidents caused by 1 million casino visitors to exceed those by 1 million Disney World visitors because a large proportion of casino visitors are adults relative to Disney World visitors, which are disproportionately young children. ${ }^{9}$ One would expect children to be less likely than adults to commit Index I crimes. ${ }^{10}$ Even if we excluded children from the comparison of Las Vegas and Orlando crime, one could argue for any number of reasons that adult casino visitors are more likely than adult Disney World or national park visitors to commit crimes. But the GM comparisons simply fail to enlighten us on this issue (GM 2006, pp. 32, 34). ${ }^{11}$

Third, the GM analysis fails to account for the length of visits. The average length of visit to the Mall of America is likely to be much shorter than the average visit to Las Vegas, and this may have an impact on the likelihood or ability to commit a crime. If instead GM had presented their data in terms of visitor days, for example, crime rates across the different venues would be presented in a consistent scale. As it is presented by GM, however, the data do not support the GM conclusions regarding visitors' propensities to commit crimes.

It is quite likely that the number of crime incidents will increase in a county after the introduction of casinos - or any other tourist attraction. To be sure, there may be any number of explanations for crime. Increases in crime are likely due to offenses by both county residents and visitors; the victims include both residents and visitors. This becomes important when considering the validity of GM's crime rate measure. 


\section{MEASURING THE CRIME RATE}

In their section on "estimation strategy" GM explain crime rates and attempt to address what is surely the most serious problem in their paper: county level visitor data are not available. This was the primary topic addressed in a recent exchange between myself and GM in Econ Journal Watch (EJW; Walker 2008a, b; GM 2008a, b). In the EJW exchange I explain that the GM crime rate will tend to overstate the effects of casinos on crime, whether measured as risk to county residents or the estimated costs of crime caused by casinos. However, GM claim that I misinterpreted what they were trying to measure in their original analysis. Even after the EJW exchange, I would argue that their explanations of what they are trying to measure and their justification for using the crime rate they do are weak. How the crime rate is measured can obviously have a significant impact on the conclusions drawn from an empirical analysis. This is certainly the case in the GM paper (2006), so it is important to discuss here. Readers interested in a more detailed discussion may wish to see the EJW exchange.

As a starting point of discussion, consider how a standard crime rate is measured:

$$
\begin{aligned}
\text { crime rate } & =\frac{\# \text { of crimes committed }}{\text { population }} \times 100,000 \\
& =\text { crimes per } 100,000 \text { people }
\end{aligned}
$$

If we let $C$ be the number of crime incidents and $P$ be the population, then the crime rate in (1) can be expressed as $\frac{C}{P} \times 100,000$. This rate gives good information on the likelihood of a person being victimized by crime, and is reliable and easy to interpret if we are discussing national crime rates, for example. Indeed, this crime rate is the traditional crime rate which is typically used in referring to national crime rates through time, for example.

Relative to the U.S. population the number of tourists is small. So an adjustment for visitors and the crimes they commit is not likely to significantly affect the U.S. crime rate. However, if one is considering a very small area (county) that has a large tourist attraction, then the crime rate must be adjusted to account for the crimes committed by visitors and for the increase in the population at risk of being victimized by crime. ${ }^{12}$ If the population at risk is not adjusted to reflect the volume of visitors, then the resulting crime rate will overstate the actual risk of a person being victimized by crime.

\subsection{Adjusting the Crime Rate for Tourists}

Several authors have discussed how visitors or tourists should be considered when analyzing the crime rate. Nettler (1984, p. 48) explains, 
The rationale for the computation of [crime] rates is a predictive one... To increase the accuracy of forecasts, a rate should be "refined" so that it includes in its denominator all those persons and only those persons who are at risk of whatever kind of event is being tallied in the numerator.

Nettler describes rates that do not correctly represent the population at risk as "crude" (p. 48). Boggs (1965) gives the example of central business districts, which attract large numbers of visitors. She explains that ignoring the visitors will produce spuriously high crime rates (p. 900). Giacopassi $(1995$, p. 7) offers a similar view:

It would be possible to have a casino and to have a vast amount of crime in a jurisdiction where there were no residents. This presents a dilemma: with no residents, there would be no denominator in the crime equation, so there could be no "official" crime rate. Clearly, calculating crime and crime rates without taking into account the population at risk can lead to wildly inappropriate conclusions.

Curran and Scarpitti (1991) explain, "it is problematic to accept a rate based exclusively on the resident population. In fact, the FBI [the source of the GM crime data] shares this concern" and warns,

The Uniform Crime Reports give a nationwide view of crime based on statistics contributed by state and local law enforcement agencies. Population size is the only correlate of crime utilized in this publication. While other factors listed above are of equal concern [this list includes stability of population with respect to commuting patterns and transient factors], no attempt is made to relate them to the data presented. The reader is, therefore, cautioned against comparing statistical data of individual reporting units from cities, counties, states, or colleges and universities solely on the basis of their population. (Quoted from Curran and Scarpitti 1991, p. 438)

Miller and Schwartz (1998) also discuss this issue in detail. They are critical of a variety of studies that have ignored the effect of tourism on the population at risk when calculating crime rates.

To illustrate the effect of visitors (tourists) on the crime rate, let $C_{R}$ be the crimes committed by residents and $C_{V}$ be crime committed by visitors. Also let $P_{R}$ be the resident population and $P_{V}$ be the population that is visiting. Then the total number of crimes committed will be $C_{R}+C_{V}$, and the population at risk is $P_{R}+P_{V}$. We can rewrite the crime rate from equation (1) as $^{13}$ 


$$
\text { Crime rate }=\frac{C_{R}+C_{V}}{P_{R}+P_{V}}
$$

For the U.S. as a whole, $C_{V}$ and $P_{V}$ are relatively small and could be ignored without consequence. But if we are interested in the crime rate for a single county that is attracting a relatively large number of visitors, then it is critical to account for these people in both the numerator $\left(C_{V}\right)$ and denominator $\left(P_{V}\right)$ of the crime rate. Otherwise, the interpretation of the crime rate for a tourist county will be very different from the crime rate for non-tourist counties.

\subsection{Grinols and Mustard on the Crime Rate}

GM introduce new terminology in addressing which crime rate to use. They discuss two crime rates, "undiluted" and "diluted." Their "undiluted" rate - what Nettler (1984) refers to as a "crude" rate - is shown using our notation from above:

$$
\text { "undiluted" crime rate }=\text { crude crime rate }=\frac{C_{R}+C_{V}}{P_{R}}
$$

Note that crimes committed by visitors are counted in the numerator $\left(C_{V}\right)$, but the number of visitors $\left(P_{V}\right)$ is excluded from the denominator in (3). When the number of visitors $\left(P_{V}\right)$ is added to the population measure, GM call the result the "diluted" crime rate. This is what Nettler (1984) refers to as a "refined" rate; it is simply our original crime rate in equation (2):

$$
\text { "diluted" crime rate }=\text { refined crime rate }=\frac{C_{R}+C_{V}}{P_{R}+P_{V}}
$$

The crime rate used by GM is the "undiluted" one, $\frac{C_{R}+C_{V}}{P_{R}}$, which is greater than the "diluted" crime rate, $\frac{C_{R}+C_{V}}{P_{R}+P_{V}}$, when $P_{V}>0$. They have no choice but to use the "undiluted" rate, of course, because they do not have county visitor data. ${ }^{14}$ But does using the "undiluted" crime rate make economic sense?

GM's discussion of which crime rate to use (GM 2006, pp. 34-35) is surprisingly weak, given how important the crime rate is in their analysis. They argue that the appropriate crime rate depends on "what questions the researcher wants to answer" (GM 2006, p. 34). GM explain that those who support using the "diluted" rate often justify it by suggesting that it better reflects the residents' likelihood of being victimized (GM 2008a, p. 22). GM provide an example to show that this need not always be the case (GM 2006, 
pp. 34-35), ${ }^{15}$ and state that their primary interest is not the risk to residents (GM 2008a, p. 22). Instead, they explain, "In this study we are interested in the costs to the host county associated with a change in crime from whatever source. We are therefore interested in the total effect of casinos on crime, and thus use the undiluted crime rate..." (GM 2006, p. 35).

It is not clear that use of the "undiluted" rate follows from a concern for the "total effect of casinos on crime." In their first EJW reply, GM reiterate this and explain, "In other words, because crime perpetrated in a give geographical area can impose costs that fall on local taxpayers, it is appropriate to consider the total number of crime incidents relative to the local population and tax base" (2008a, p. 22). This certainly makes sense if one can estimate the costs of crime that are actually borne by the local population/taxpayers. Yet, GM do not distinguish between resident and visitor victims in their analysis. Their "diluted" crime rate, $\left(C_{R}+C_{V}\right) / P_{R}$, implicitly assumes that all crimes are perpetrated against residents. Therefore, the costs of crime are implicitly assumed to be borne entirely by residents. This is inappropriate, as the discussion in Section 2 suggests that crime victims include casino county residents and visitors.

In their second EJW reply GM indicate that the denominator of the crime rate is "irrelevant" to the social costs of crime. What is important, they argue, is the absolute number of crime incidents (2008b, p. 160). It is not clear that showing an increase in the absolute number of crimes in a county, ignoring visitors, has much meaning at all. It certainly does not indicate anything about the risk of being victimized, whether society is more or less safe, or the social costs of crime caused by casinos.

\subsection{Estimated Costs of Crime}

Even ignoring the crime rate issues above, the GM cost of crime estimates are questionable. From reading their abstract (GM 2006, p. 28) and vague description of cost calculations (p. 41), a reasonable reader may interpret their estimated cost of casino crime as being $\$ 75$ per adult casino county resident (for 1996). Recall GM's explanation for choosing to use the "undiluted" crime rate:

Grinols and Mustard $(2006,35)$ clearly states, "In this study we are interested in the costs to the host county associated with a change in crime from whatever source. We are therefore interested in the total effect of casinos on crime, and thus use the undiluted crime rate based on equation (3)." In other words, because crime perpetrated in a given geographical area can impose costs that fall on local taxpayers, it is appropriate to consider the total number of incidents relative to the local population and tax base (GM 2008a, p. 22). 
One would therefore expect that they would attempt to estimate the costs of crime to casino county residents. This was the focus of my second EJW comment (Walker 2008a). The GM estimated cost of crime ( $\$ 75$ per adult $\left.{ }^{16}\right)$ is flawed because the majority of the estimated costs GM use in their estimate are quality of life losses, pain and suffering, and other intangible costs that are borne by the crime victims (Miller et al. 1996, p. 9; Walker 2008b, pp. 150-151). Many or at least some - of the crime victims are likely to be casino county visitors. But the GM analysis does not distinguish between resident and visitor crime victims. It effectively attributes all of these costs of crime to casino county residents - since the denominator of their crime rate includes only $P_{R \cdot}{ }^{17}$ Although GM claim to be interested in the costs that fall on casino hosting counties, their cost estimate clearly does not represent only costs to casino counties. Given their seemingly conflicting explanations in their original paper and their EJW replies, as well as their vague explanations of their calculations, it is unclear exactly what - if anything - GM's estimated cost of crime represents. Unfortunately, politicians are likely to take GM's $\$ 75$ cost estimate at face value.

\subsection{Law Enforcement}

Another potentially serious problem with interpreting the GM crime analysis is that they only superficially account for changes in law enforcement. This issue is important because changes in funding or enforcement priorities could easily affect county crime rates, in a number of ways (Albanese 1985, p. 41).

Casino taxes and fees are often used to supplement police resources in local jurisdictions. The increase in policing may explain increased arrests simply because there are more police to uncover evidence and make arrests. Or with more law enforcement there may be more reports of crime. Alternatively, one could argue that the greater police presence should have a deterrent effect and may result in fewer offenses and arrests. Unfortunately, police resources and other law enforcement data are not readily available at the county level (GM 2006, p. 39), so GM were unable to account for these in the model.

There are two other potentially serious variables ignored by GM. First, the level of police resources is likely to vary directly with the number and/or size of the casinos in that county. Yet there is no direct accounting for this with an enforcement variable, nor is there any accounting for the number or size of the casinos, or the level of tourism, elsewhere in their model. Second, the authors ignore any changes in laws regarding the index crimes or their penalties. During the sample period (1977-96) one would assume that some laws could have been enacted or changed that might have affected crime rates. ${ }^{18}$

In lieu of better data, GM attempt to account for law enforcement by including arrest rates as an explanatory variable. They find that the casino effect on crime becomes stronger. They do this despite admitting that the arrest rates are often undefined: "For some offenses including the arrest rate eliminated over 30,000 [of the 58,000] observations" (GM 2006, p. 39, note 20; p. 35). Their explanations of the data used and the results are limited in detail, so it 
is difficult to address the validity of these results. However, it is interesting to note that in an earlier version of the paper GM argued against using the arrest rate in the model (GM 2001, p. 17).

In another cursory attempt to address the law enforcement issue, GM included variables that estimated the probability of capital punishment (GM 2006, p. 39). Yet, none of the crimes which GM attribute to casinos are capital offenses (murder was insignificant), so it is difficult to argue that these added variables would be at all relevant. Consider one of the variables, calculated "the number of executions in the first three quarters of the current year and last quarter of the previous year divided by the number of people sentenced to death six years ago" (GM 2006, p. 39, note 21). It is doubtful that this variable would have any explanatory power in the effect of casinos on crime.${ }^{19}$ Nor would it necessarily serve as a reliable proxy for the state's attitude toward crime and punishment.

Considering their lack of county-level law enforcement and visitor data, one can conclude that law enforcement has been effectively ignored in the GM analysis and results. Instead of acknowledging this fact, the authors list anecdotal evidence from police presentations at a 1999 conference and the general observation that police enforcement expenditures typically increase when a casino opens (GM 2006, p. 40). They assert, "Because we cannot measure all these additional resources that reduce crime, our estimates without enforcement variables tend to understate the effect of casinos on crime" (GM 2006, p. 40; also see p. 44).

\subsection{Summary}

This section has discussed several problems with the GM crime rate measure. Clearly, the crime rates estimated by GM are of questionable validity. They likely overstate the effects of casinos on crime. Obviously with a large influx of tourists a county will see an increase in the number of crime incidents. So GM's measure of crime in casino counties tells little about the impact of casinos on crime. The monetary costs of crime reported by GM are also questionable, as they do not reflect the costs borne by casino county residents. Readers of the GM study should keep these issues in mind as they contemplate GM's findings.

\section{CRIME DATA}

There are two potential problems with the GM crime data, the Uniform Crime Reports (UCR). The UCR data at the county level are based on voluntary crime reporting by a number of agencies within each county. The crimes reported by the various agencies are aggregated to arrive at the county-level UCR data. The problem arises from how missing crime data are imputed.

For the 1977-93 period, data were classified and reported three ways (UCR 1994, p. ii): (i) data from agencies that reported all 12 months were 
used as submitted; (ii) data from agencies that reported 6-11 months were adjusted to an annual basis ${ }^{20}$; and (iii) data from agencies that reported fewer than 6 months were deleted, so that these agencies had no effect on the county crime rate. ${ }^{21}$ The UCR explains that the reason for this imputation method was to "ensure cross-sectional data comparability and quality," but it warns, "if there were major changes in the [agencies] reporting in a county across years, artifactual changes in the longitudinal data for a county could be introduced because of potential variation in the type of [agency] used to compute imputed county totals and rates each year" (UCR 1994, p. ii).

In order to make the data more useful for longitudinal analyses, in 1994 the UCR changed its method of imputing missing data (p. i). Data from agencies reporting all 12 months were still used as reported. Crime from agencies reporting 3-11 months were adjusted to annual rates, and data from agencies reporting 2 months or less were replaced with rates based on similar agencies in the state that reported all 12 months (p. ii).

There are two problems with the UCR data as they relate to the GM study. The first is that the imputation for crime by non-reporting agencies may introduce anomalies into the GM crime data. ${ }^{22}$ Maltz (1999, p. 26) explains, "Most observers believe that the effect on the estimate of the overall crime rate in the United States would be minimal, but that it could be quite problematic when investigating the crime rate for a smaller unit such as a State or county, or when looking at rural crime rates." ${ }^{23}$ Maltz and Targonski (2002) believe the problems are so serious that, "until improved methods of imputing countylevel crime data are developed, tested, and implemented, they should not be used, especially in policy studies" (p. 297). ${ }^{24}$

The second problem is that, although the GM sample period is 1977-96, the authors' model apparently does not account for the 1994 change in UCR data reporting. The UCR data codebook includes a section titled, "Break in Series," in which it warns, "data from earlier year files should not be compared to data from 1994 and subsequent years because changes in procedures... may be expected to have an impact on aggregates for counties in which some [agencies] have not reported for all 12 month" (UCR 1994, p. i; emphasis added).

It difficult to speculate on how exactly these data issues might affect the GM analysis, but the effect could be serious. Much of the U.S. casino expansion occurred in the early 1990s (1991-93). ${ }^{25}$ As discussed below, GM find crime in casino counties starts to rise four or five years after casinos are introduced. For counties that adopted casinos in the early 1990s, this increase in crime rate corresponds to 1994 or later - after the UCR imputation change. It is possible that the crime effect found by GM results from the UCR data imputation and/or the 1994 change.

\section{CASINO COUNTY VARIABLES}

The ideal measure of casino gambling, as GM explain, would be gross revenue or profits (GM 2006, p. 29), or some other measure of the intensity or 
volume of gambling. Although these data are available for commercial casinos, they are not for Indian casinos. However, there are other available measures that could have been used. Betsinger (2005, p. 30) measures volume by including variables for the numbers of slot machines and table games, bingo seats, electronic or video bingo seats, video gaming machines, and video lottery terminals. Reece (2008) uses turnstile count, but this is not available in all states. Walker and Jackson (2008) use the square footage of Indian casinos as a proxy of volume. Instead of using some measure of volume, GM simply use a dummy variable for the first year in which any casino opened in each county (GM 2006, p. 35) and lead and lag dummies to account for the existence of casinos for various lengths of time. This choice of variables to account for casino activity creates some potential problems in the GM model.

\subsection{Limitations of the Casino Dummy Variables}

The GM casino dummy will show how sensitive crime rates are to the opening of a casino in a county. But if there is a relationship between casino gambling and crime, one would expect that relationship to be dependent, at least in part, on the number of casinos, the size of the casinos, their volume, and even the types and number of games offered. But the GM first year dummy cannot pick up any of these variations. Their model essentially treats the Las Vegas strip mega-casinos the same as a small isolated casino in Colorado. This is unrealistic, and it makes the interpretation of their results problematic. Policymakers are likely to interpret the GM results as general the likely effects of casino adoption in any particular county. This is clearly the implication of GM's abstract (2006, p. 28). However, such an interpretation of the GM results is incorrect.

Furthermore, the dummy variable technique used by GM to denote casino counties will pick up any differences in the crime rate between casino and non-casino counties, not just those differences that are due to the presence of casinos. In general, anything that distinguishes the casino counties from national norms will be picked up by the dummy. Even the effects of the included demographic and other normalizing variables, to the extent that their impact on the crime rate differs between casino and non-casino counties, will be picked-up by the dummy. Thus, inferring that a positive and significant dummy coefficient for casino counties implies a higher crime rate in those counties because of the presence of casinos is simply not justified by sound econometric interpretation.

\subsection{Casino vs. Non-casino Tourism}

The GM paper compares crime rates in "casino" counties to those in "noncasino" counties. They find that crime rates drop in both, but they drop faster in non-casino counties. Although it would seem obvious that a comparison of casino versus non-casino counties would isolate the crime caused by casinos, 
this is not necessarily the case because the "casino" and "non-casino" county dichotomy does not clearly isolate the casino effect on crime.

Recall that GM do not account for visitors - tourism - in the denominator of the crime rate. Now consider that there are many different types of tourist attractions in the U.S. Let us classify them as either "casino-tourism" or "other-tourism." We can then classify the types of counties in the U.S. as in Table 2.

On closer examination, it becomes apparent that the GM analysis is actually a comparison of "casino-tourism" and "casino-and-other-tourism" counties as a group - to an aggregate of "other-tourism" and "no-tourism" counties. Although GM claim to show the marginal impact of casinos on crime, their data and analysis do not allow them to tease out the effect of casinos on crime. Their findings may simply be picking up a tourism effect on crime, since counties they classify as "casino" may have other tourist attractions as well. Even if we ignore all other potential problems discussed in this paper, the GM results can only show that crime in casino-tourism and/or casino-and-other-tourism counties - as a group - is greater than crime in other-tourism and no-tourism counties - as a group. We could learn something about county level crime due to casinos if we analyzed casino-tourism counties versus other-tourism counties, but only then if a refined ("diluted") crime rate is used.

In short, GM have not provided any evidence that higher crime rates in casino counties are caused by the presence of casinos. Aside from the tourism issue discussed above, there are a number of other (unobserved) variables that might explain the higher crime rate in casino counties. The point is that the GM casino variable is unable to distinguish between crime caused by casinos and crime caused by tourism or other idiosyncrasies of casino counties.

\subsection{Sample Self-selection Bias}

Even carefully executed and elegant econometric analyses can be rendered invalid if the samples are biased. GM claim that "[by] conducting the most exhaustive investigation and utilizing a comprehensive county-level data set that includes every U.S. county, we eliminate sample selection concerns" (GM 2006, p. 33). It is certainly true that GM utilize every available county in the U.S., so that the researchers have not chosen a biased sample.

\section{TABLE 2}

U.S. Counties Classified by Tourism Type

\begin{tabular}{ll}
\hline \multicolumn{1}{c}{ County Type } & \multicolumn{1}{c}{ Description } \\
\hline no-tourism & There is no significant tourism in the county. \\
casino-tourism & Casino gambling is the only significant tourist \\
& attraction available in the county. \\
other-tourism & There are non-casino tourist attractions only. \\
casino-and-other-tourism & There are casinos and other tourist attractions \\
\hline
\end{tabular}


However, the possibility remains that prior to the introduction of casinos, the counties might have had higher crime rates than non-casino counties. GM discuss the lead periods and note that the lead crime rates on casino counties are positive and significant relative to non-casino counties. Once the control variables are added to the model, however, the lead crime coefficients on casino counties are positive but not significant, except for auto theft. The implication is that prior to casinos opening, casino counties were no different with respect to crime than non-casino counties.

Although GM use all U.S. counties in their studies, the counties nevertheless self-select into the "casino county" category by their government's decision to permit casinos. ${ }^{26}$ As a result, the GM casino county sample is potentially biased. As GM note (2006, p. 36), it is commonly thought that casinos are more likely to be placed in high-crime areas. Atlantic City, NJ, and Tunica County, MS, may demonstrate this. Consider that the GM lag 5 crime rates are the highest of any reported lag period at the end of their sample period in 1996. The highest crime rates in the model are thus associated with counties that legalized casinos in 1991. This was a period of rapid casino adoption (GM 2006, p. 38) and coincides with a U.S. recession. Indian nations are also responsible for a large proportion of casino adoptions in the U.S. It is an unfortunate fact of U.S. history that Indian nations are often relatively poor and face more economic hardship than non-Indian communities. Since casino gambling is often sold as a potential economic growth or tax revenue strategy, there is good reason to expect that counties with relatively poorly performing economies might be more likely to introduce casinos and to do so more quickly than counties that are better off economically.

GM do not adequately account for the possibility of self-selection among the counties. Arguing that the lead period casino crime rate estimates were not significantly different from those for the non-casino counties (GM 2006, p. 36) does not preclude the possibility that relatively disadvantaged counties legalized casinos sooner than wealthier counties. In the lead periods the crime coefficients for casino counties were positive, even with the control variables included. This gives some indication that casino counties had more crime or were more prone to crime prior to the introduction of casinos. These counties may have differed from non-casino counties in both observed and unobserved ways.

Fink, Marco, and Rork (2004) demonstrate the importance of accounting for state self-selection in the case of lottery adoption and the lotteries' impact on state budgets. GM could have used the Heckman (1979) two-step, or some other method, to control for self-selection of counties into the casino category. In the absence of this or a similar treatment to check for sample self-selection bias, the results of the GM study must be qualified. ${ }^{27}$

\section{OTHER ISSUES}

The GM paper makes a variety of strong conclusions that have had, and will continue to have, a significant impact on policy and political and 
academic debate over casino gambling. For example, in the abstract they claim,

Most factors that reduce crime occur before or shortly after a casino opens, whereas those that increase crime, including problem and pathological gambling, occur over time. The results suggest that the effect on crime is low shortly after a casino opens, and grows over time. Roughly $8 \%$ of crime in casino counties in 1996 was attributable to casinos, costing the average adult $\$ 75$ per year. (GM 2006, p. 28; also see p. 41)

This and other conclusions by GM are based on a series of questionable assumptions and interpretations. The fact that GM often give unclear explanations for their calculations complicates this. Still, the extent to which their analysis supports their conclusions is debatable.

\subsection{Vague Explanations}

Given the importance of the subject of their study and its relevance to ongoing policy debates, one would expect that GM would have clearly explained how they came to their various cost estimates and conclusions. In addition, one should expect that, in the spirit of academic research and debate, the authors would have been transparent so that other researchers could replicate or even critique their analysis. Unfortunately, in key areas developing their conclusions, GM fail to clearly explain what they have done. For example, in calculating the "fraction of observed crime due to casinos" and the "implied cost of additional crime" (GM 2006, p. 41), GM explain:

Summing the estimated number of crimes attributable to casinos for each county, taking into account how many years the casino was in operation, and dividing by the casino counties' total population measures the contribution of casinos to observed crime. Estimates of the share of crime attributable to casinos in 1996 for individual crimes ranged between 5.5\% and $30 \%$.

It is unclear whether all crime rates, or only the lag 5 rates, were summed. Just prior to and after the above-quoted discussion, GM explain calculations that are based solely on the lag 5 crime estimates. The first case (GM 2006, pp. 40-41) deals with calculating an estimate of the number of crimes that would be committed by problem and pathological gamblers if that was the one source of additional crime. The second case (GM 2006, p. 41, fourth paragraph) involves calculating the average property loss from four of the criminal offenses they study. A reasonable assumption is that GM have also used only the lag 5 crime rates in calculating the fraction of observed crime due to casinos and the cost of that crime. 
However the authors calculated the fraction of crimes attributable to casinos and the costs of these crimes, any results based on lag 5 crime rate estimates only are surely biased and will overstate the casino effect on crime. This is because the lag 5 rates are based on a relatively small sample of casino counties, only 49 of the 178 casino counties in 1996 (GM 2006, p. 41). These were among the first counties to adopt casinos, and the lag 5 crime rates are the highest of any lag period reported in the study. One cannot argue that the lag 5 counties are representative of all 178 casino counties. Certainly using the sample of casino counties with the highest crime rates leads to an overstatement of the true crime effect of casinos in general.

Another area in which GM are extremely vague in their explanation is with the estimated costs of casino related crime. This issue was discussed earlier in this paper, as well as in the EJW exchange.

The vagueness with which GM (2006) explain their calculations is surprising, especially when one considers how much space the authors dedicated to storytelling, apparently in an effort to demonstrate how terrible gambling can be. GM spend approximately 80 lines (nearly a full page of text) quoting and citing newspaper article headlines and describing other anecdotal evidence of the harms of casino gambling; these references are peppered throughout their paper. ${ }^{28}$ A more detailed explanation of their empirical results and cost calculations would have certainly been a better use of text space in an academic journal.

\subsection{Do GM's Results Show a Time Trend of Crime?}

GM conclude that the crime rates "tend to increase over time after a lag of 2-3 years" (GM 2006, p. 36). As they explain in the paper's abstract, "Most factors that reduce crime occur before or shortly after a casino opens, whereas those that increase crime...occur over time. The results suggest that the effect on crime is low shortly after a casino opens, and grows over time" (GM 2006, p. 28; also see their Tables 3 and 4, pp. 36, 37). There is a lengthy discussion of the "time pattern" of the estimated crime effects (GM 2006, p. 40). Their figures 4 and 5 (GM 2006, pp. 38 and 39, reproduced in the appendix to this paper) illustrate the estimated crime rates. The reader may reasonably infer from these figures and the GM discussion that the results for different lag years represent trends in crime rates, and these trends would continue in subsequent years. They explain, "with few exceptions...later lags showed comparable or greater estimated effects to the fifth year lag" (GM 2006, p. 37, note 16). They reiterate this in their EJW reply (2008a, p. 29). But this claim appears to apply only to larceny and auto theft. Based on the tables from an earlier draft of the GM paper, crime in most categories either levels off or falls after the fifth year. (See the appendix for tables from an early draft of the GM study showing lag 6 and 7.)

The GM "time trend" interpretation of the crime rate results is questionable. ${ }^{29}$ This is because the GM coefficient estimates on the different lag 
TABLE 3

Casino Counties For Different Lag Periods

\begin{tabular}{|c|c|c|c|}
\hline \multirow[b]{2}{*}{ Lag \# } & \multicolumn{3}{|c|}{ Casino counties } \\
\hline & $\begin{array}{l}\text { Total } \\
\text { (178) }\end{array}$ & Nevada & Non-Nevada \\
\hline 5: casinos open 5 or more years & 49 & 14 & 35 \\
\hline 4: casinos open 4 or more years & 73 & 14 & 59 \\
\hline 3: casinos open 3 or more years & 105 & 14 & 91 \\
\hline
\end{tabular}

Source: Author's presentation of information provided by GM (2006), p. 35.

periods (1-5) are based on varying samples of casino counties. That is, each lag period contains a different group of casino counties, although most of the counties are included in more than one lag period. ${ }^{30}$

Table 3 summarizes the total number of casino counties included in each GM lag period, and the number of Nevada and non-Nevada counties, based on the information given in GM.

Starting with lag 5 in the top row of the table, there were 49 counties that had casinos five years or more. The next row (lag 4) indicates that 73 counties had casinos for at least four years. These include the 49 counties from lag 5 plus 24 counties that more recently had casinos open. The last row (lag 3 ) includes the 73 counties from lag 4, plus 32 new counties. The point is that the estimated crime rates for each lag period are based on different samples of counties.

Given this information, it is inappropriate to interpret the differences in estimated crime rates from lag 1 to lag 5 as a trend in the crime rate, since the sample of counties for each lag period is somewhat unique. It is true that the estimated crime rates in lag 5 are higher than those for lag 4, but this simply means that the casino counties used to calculate lag 5 crime rates had worse crime - as a group - than the sample of counties used to derive the lag 4 coefficient estimates, as a group. ${ }^{31}$ The higher crime coefficient estimates in lag 5 do not necessarily imply that the average casino county will see increasing crime rates between four and five years after introducing casinos.

Inferring anything from the results about how the casino county crime rates move through time is questionable unless the same sample of casino counties is used throughout. For example, had GM used the same 49 counties from lag 5 to calculate the crime rates in all lag periods, then the changes in coefficients would correctly be interpreted as a trend in crime rates.

\subsection{The Marginal Impact of Casinos on Crime}

GM's Tables 3 and 4 (2006, pp. 36, 37) show that most of the lead period crime coefficients are positive. Once GM introduce control variables (GM 2006, Table 4) the statistical significance of these coefficients disappears, but the coefficients are still mostly positive for casino counties. If we are interested in the marginal impact of casinos on crime, then it seems appropriate 
TABLE 4

Casino Crime Rates, Estimated Coefficients

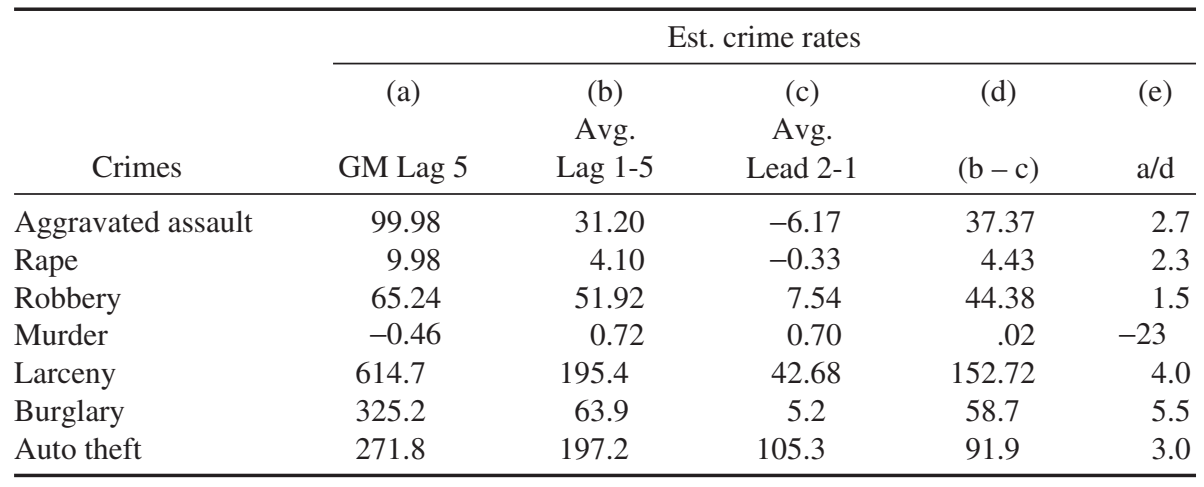

Source: Data in (a) from GM Table 4, p. 37; other data from author's calculations.

that we should be comparing the post-casino county crime rates (lag periods $1-5$ ) with the pre-casino rates (lead periods 2 and 1 ) in the same counties. The change from the lead to the lag crime rates would be an indication of the marginal impact of casinos on crime. However, GM base their conclusions only on the lag period crime rates (either some average of them or the lag 5 rates only), without subtracting the lead period crime rates. The result is that GM may overstate the marginal effect of casinos on crime.

Without having the GM data, one way to calculate this marginal impact is to use the GM Table 4 results and subtract the means of the crime rates in the lead periods from the means of the crime rates in the lag periods. The difference between the mean lag and lead crime rates would give us an indication of the marginal impact of casinos on crime. In addition, this measure would take into consideration all casino counties, not just the 49 counties in lag 5 that happened to have the worst crime rates - which GM use in coming to some of their conclusions. ${ }^{32}$

In Table 4, above, the GM estimated crime rates for lag 5 (taken from GM 2006, Table 4, p. 37) are reproduced. Several other calculations are also shown. When we calculate the means of the crime rate coefficient estimates for lag periods 1 through 5, column (b) shows them to be drastically lower than the GM lag 5 results (a) used to drive some of their cost estimates. When the means of the lead coefficients (c) are subtracted from the mean lag estimates (b), we get a rough measure of the average change in crime rates resulting from the introduction of casinos, shown in (d). Finally, column (e) represents the GM estimated lag 5 coefficients divided by the difference between the lag and lead mean crime rate estimates (calculated as a/d). The resulting figure represents the overestimate of the GM lag 5 crime rate relative to the mean crime rate change. The results of this simple analysis suggest that GM may have overestimated the effect of casinos on crime by a factor of 1.5 to 5.5. ${ }^{33}$ The only case in which the GM methodology appears to have underestimated the casino effect is for murder. 
The means of the lead crime rates from GM (shown in column c of Table 4 , above) includes all 178 casino counties. The calculated mean crime rates for the lag periods are based on varying samples of counties, as explained above in discussing the alleged "time trend" in crime rates. For example, lag 1 certainly includes most of the U.S. casino counties; it excludes only the counties that introduced casinos in the last year of the sample period.

The casino counties with the worst crime rates (lag 5) are over-represented in the Table 4 calculations. These are the counties that had casinos for at least 5 years, and they are included in lag 5, 4, 3, 2, and lag 1 measures. However, a county having casinos only 3 years would be counted only in lag 3,2 , and 1. If counties facing relatively bad economic situations are among the first to legalize casinos, which is consistent with the findings that lag 5 casino counties have the highest crime rates, then the calculation of the mean crime rates in the lag periods will tend to overstate the average crime rate in casino counties. This suggests that GM overstate the crime effect of casinos by at least the factors indicated in column (e) of Table 4 above.

\section{CONCLUSION}

Several other studies have examined crime rates while accounting for visitors in particular casino markets. Albanese (1985) and Curran and Scarpitti (1991) analyze Atlantic City crime. Accounting for tourists in the population at risk, they find no relationship between casinos and crime. Stokowski (1996) studies the effects of casinos on crime in three small Colorado mining towns. She finds that crimes/population rises after casinos open, but accounting for visitors, crimes/vehicle count actually fall. In a more recent and comprehensive study, Stitt et al. (2003) examine six casino communities paired with non-casino control communities. They find that some casino communities see increases, while others see decreases in crime. They conclude that "crime does not inevitably increase with the introduction of a casino" (p. 253). GM do not dispute these results - they ignore them. Reece (2008) examines crime in Indiana in a county-level analysis. Adjusting for casino turnstile count and county hotel rooms as measures of casino activity and visitors, Reece finds that casino activity may actually lower crime. On the other hand, it would not be surprising if tourist areas act as "hot spots" for crime and attract criminals. One might even expect that casino tourism to be worse than other types of tourism. But the GM (2006) study simply does not legitimately address the issue. $^{34}$

This paper highlights some of the important problems in the GM study of the relationship between casinos and crime in the U.S. When casinos open in an area, the absolute number of crimes committed will rise, just as it would in any new tourist area. But this is all the GM study really shows. The interesting and important question is whether casino-related tourism creates more crime than other forms of tourism. The GM analysis does not answer that question. 
In his crime study Albanese (1985, pp. 40-41) explains, "Crime statistics can be extremely misleading when they fail to account for (1) changes in the population at risk, (2) changes in criminal opportunities, (3) changes in law enforcement resources and priorities, and (4) changes in crime elsewhere in the State." The GM paper fails to account for the first three factors.

(1) The GM crime rate ("undiluted" or "crude") excludes visitors from the population at risk resulting in a likely overestimate of the crime rate in casino counties.

(2) The GM model does not attempt to account for the fact that a large inflow of casino tourists represents a significant change in criminal opportunities.

(3) GM make only superficial attempts to consider any changes that may have occurred in terms of law enforcement spending, staffing, or priorities. Theoretically, such changes could have some positive and some negative impacts on the crime and arrest rates.

In addition to the crime rate issues, the crime data used by GM are questionable because of data imputation and the 1994 changes in method. The GM casino variable is unable to distinguish between crime in casino counties caused by casinos and crime caused by other factors. GM's estimated cost of crime caused by casinos is questionable. There may also be a sample selection bias since casino counties self-select into that category. Finally, GM make a number of conclusions that are not justified by their empirical results. Collectively, these problems raise serious doubt of the validity of the GM paper and its conclusions. ${ }^{35}$

Although GM present their study as being the "most exhaustive ever undertaken" (GM 2006, p. 43) and their results as being "lower bounds on the true effect [of casinos on crime]" (GM 2006, p. 44), readers should be wary. Each of the problems in the GM analysis identified in this paper has the effect of increasing the apparent effect of casinos on crime. GM have likely overstated the impact of casinos on crime. This is not to suggest that casinos do not cause crime; other studies have found mixed results. The point is that the GM paper is flawed. A clearer understanding of the casino-crime relationship is of critical importance to jurisdictions worldwide that are grappling with the casino legalization issue. The issues and pitfalls discussed in this paper can provide useful information for future researchers.

\section{NOTES}

1. The Alberta Gaming Research Institute (AGRI, http://gaming.uleth.ca) has an extensive online database of gambling research. Walker (2007) provides an overview of much of the gambling research related to economic issues.

2. For example, several newspaper reports have highlighted the GM study (Morin 2006, Vitagliano 2006, Yarbrough 2006). Policy reports have utilized the study (PolicyAnalytics 2006), and recent research 
has reported the GM findings (Morse and Goss 2007, pp. 79-82). The paper has been also posted on activist websites such as the National Coalition Against Legalized Gambling (http://www.ncalg.org) and CasinoFreePA (http://www.casinofreepa.org). Recently, Grinols co-authored an op-ed piece with the co-chairman of Citizens Against Casino Gambling in Erie County (Grinols and Rose 2007). Another recent newspaper article (Monahan 2007) examines research motivations.

3. A recent exchange between the author and Grinols and Mustard over some of the issues discussed in this paper was published in Econ Journal Watch (EJW; www.econjournalwatch.org) in the January 2008 and May 2008 issues. This paper was written prior to the original EJW comment. Although there is some overlap, this paper covers more topics, is more detailed, and is aimed specifically to gambling researchers.

4. This issue is discussed below. A comparison of casino counties with non-casino counties does not allow GM to isolate casino-tourism crime from non-casino-tourism crime.

5. This is an admittedly old source. There has been an enormous amount of subsequent prevalence research, generally concluding that a very small percentage of people develop gambling problems.

6. It is somewhat odd that for the information in Table 1, GM include visitors in the population measure. Later in the paper they argue that this measure may be misleading, in terms of the risk of residents falling victim to crime. This is discussed in more detail in Section 3.

7. The routine activities theory is summarized by Felson (2000).

8. The Mall of America has a number of attractions that are clearly aimed at children. Similarly, many of Branson's and Disney World's attractions are family oriented.

9. Survey data for 2005 indicate that there were about 39 million visitors to Las Vegas (Las Vegas 2006). Data from a visitor profile survey (GLS Research 2005, p. 34, Figure 22) shows that only about $9 \%$ of respondents "had any people under the age of 21 traveling with them in their immediate party." Data on the age profiles of Disney World visitors were not available, but it would be surprising if children did not make up at least half of Disney World visitors.

10. On the other hand, Felson (2000, p. 205) states that 12-25 year olds commit a disproportionate amount of crime. Albanese (1999, p. 67) reports that $18.3 \%$ of those arrested for index crimes are under 18 years old; $45 \%$ are under age 25 . Almost half (46\%) of violent crime arrests and $58 \%$ of property crimes involve individuals under age 25.

11. Without better data on criminal profiles, GM cannot discern exactly who is primarily responsible for crime in Las Vegas or at Orlando.

12. Generally, any economy with a significant portion of visitors to residents would need to account for visitors in the crime rate for the data to be meaningful.

13. For simplicity we hereafter ignore the standard practice of multiplying the rate by 100,000 .

14. See GM (2006, p. 34, note 12). Stitt, Nichols, and Giacopassi (2003, p. 261) overcome this problem by estimating the number of "person trips." Reece (2008) uses casino turnstile count as a proxy for casino activity, and the number of hotel rooms in counties as a measure of visitors for his analysis of Indiana casino crime.

15. I elaborate on their example much more in the EJW exchange. Note that GM do not offer a real example from an actual empirical study. Nor do they cite any literature which might support their contention.

16. It is unclear to me whether this is supposed to apply to casino counties only, as their original paper appears to suggest (GM 2006, p. 41), or to the U.S. overall, as their EJW reply seems to indicate (GM 2008b, p. 160). I leave this up to readers to decipher. In either case, their cost estimate is suspicious.

17. Knowing where the crimes occur (casino-based or community-based) would provide some insight into the relative probabilities of being victimized for residents and visitors. Curran and Scarpitti (1991, p. 444) find that about $64 \%$ of Atlantic City crime from 1985-89 was committed on casino premises. The GM study does not distinguish between on- and off-premises crimes.

18. Since counties may change laws at different times, county dummies would not pick up such changes. The lead- and lag-variables on casino would also not pick up such effects, since these dummies are the same for all counties. To account for these changes an interaction term between the county and changes in law enforcement would be necessary.

19. GM note that when these variables were added, "the results are qualitatively the same as for the base regression" (GM 2006, p. 39, emphasis added). This could mean that the crime effect in casino counties was positive but insignificant; the authors are not clear on this.

20. This is done by multiplying the number of reported crimes by a factor of $12 / N$, where $N$ is the number of months crime was reported.

21. Specifically, the crimes were deleted from the crime rate measure, as was the estimated population served by that agency.

22. GM do note that some of their observations (about 5,300) had missing data and were not included in the model (GM 2006, p. 35). However, they do not explain what the missing data are. Even if this refers to imputed UCR data, the absence of those data could still potentially affect their results. GM do indicate that they used regressions weighted by county population (GM 2006, p. 35). This could mitigate some of the data problems, to the extent that less populated counties are less likely to report 
crime. This issue is discussed in the debate between Maltz and Targonski (2002, 2003) and Lott and Whitley (2003).

23. It is surprising that GM do not discuss some of the problems with UCR data. In the context of the "right-to-carry" gun law debate, Lott and Whitley (2003, p. 186, note 6) mention that Lott and Mustard were well aware of problems with the UCR data, and that they "had compiled an eight page singlespaced list of problems." GM should have at least acknowledged that there are potential problems with the data, even if they are the best data available.

24. Many of the problems with the crime rate data are discussed in the recent study by Reece (2008), which replicates the GM analysis, but for the state of Indiana alone, and with an attempt to control for visitors.

25. Only Nevada, New Jersey, and South Dakota had commercial casinos prior to 1991.

26. This occurs after the state has legalized casino gambling.

27. In their EJW reply GM (2008a, pp. 25-28) provide a reasonable response to this issue, indicating that earlier versions of their paper dealt with self-selection in more detail. The published version of the paper (GM 2006), however, does not discuss the issue in much detail.

28. For example, see GM (2006), pp. 31, 32, 33, 37, and note 17.

29. In their EJW reply (2008a, p. 29), GM misinterpret my concern as being, "other calculations might give different numbers than the statistics we report...for the effect after five years from opening of casinos on crime rates."

30. As an extreme analogy to GM's analysis, suppose a researcher suggested that the following case represented an increasing trend in crime rates: "Crime rates rise as we go through time: county 1 (year 1 ) < county 2 (year 2 ) < county 3 (year 3 ) < county 4 (year 4)." Obviously it makes no sense to claim that this pattern of crime in different counties during different periods represents an increasing crime trend.

31. The discussion in Section 5.3 of this paper indicates several reasons that counties with worse economies may be more likely to introduce casinos sooner than counties not as bad off.

32. However, older casinos are weighted heavier than newer casinos in this calculation. This is explained below.

33. In deciding how to handle the estimated crime coefficients for the casino opening period, "Open" (GM 2006, Table 4, p. 37), I considered how including those values in the "lead" and "lag" category would affect the estimated impact of crime. Since the opening year estimates tend to be higher than the lead period averages, including the open estimates in the mean of lead periods would have lowered the calculated impact of casinos on crime. On the other hand, most of the opening year estimates are lower than most of the lag period mean rates. So including open in the lag mean calculation would have also lowered the calculated impact of casinos on crime. So the open year coefficient estimates were excluded from the calculations in Table 4 above. The result of this omission is to make the estimated crime effect from casinos higher than they would be if opening year rates were included.

34. Stitt et al. (2003) do not find strong evidence to support this conclusion.

35. Ideally, we would replicate the GM analysis using correct data and assumptions. However, the required data - county visitor count - are simply not available nationwide. Reece (2008) comes close, as he does attempt to consider visitors. However, his analysis is limited to Indiana.

36. This conclusion appears to conflict with what GM report: “...later lags showed comparable or greater estimated effects to the fifth year lag" (GM 2006, p. 37, note 16).

37. The stated reason for not including the sixth or seventh year lags is that there are even fewer counties with casinos open that long. But there is probably little practical difference between the casino county sample sizes of 35,12 , and seven, relative to the full sample of 3,165 counties.

38. The 1999 version of the paper was not published, so we should not make too much of this comparison, as there may be differences in how the analyses were performed. In any case, the comparison is at least interesting.

\section{REFERENCES}

J Albanese 'The effect of casino gambling on crime' Federal Probation (1985) 48 39-44.

J Albanese Criminal Justice (Boston, MA, Allyn \& Bacon, 1999).

American Psychiatric Association (APA) Diagnostic and Statistical Manual of Mental Disorders 4e (DSMIV) (Washington, DC, American Psychiatric Association, 1994).

S L Betsinger 'The relationship between gambling and county-level crime' (University of Maryland thesis, 2005).

S L Boggs 'Urban crime patterns’ American Sociological Review (1965) 30 899-908.

D Curran and F Scarpitti 'Crime in Atlantic City: Do casinos make a difference?' Deviant Behavior (1991) $12431-449$. 
M Felson 'The routine activity approach as a general crime theory' in S S Simson (ed) Of Crime and Criminality (Thousand Oaks, CA, Sage, 2000) pp 205-216.

S C Fink, A C Marco and J C Rork 'Lotto nothing? The budgetary impact of state lotteries' Applied Economics (2004) 36 2357-2367.

D Giacopassi 'An analysis of the Maryland Report' The House Never Loses and Maryland Cannot Win... (University of Memphis manuscript, 1995).

GLS Research Las Vegas Visitor Profile: 2005 Annual Report (Online at http://www.lvcva.com/press/ statistics-facts/visitor-stats.jsp, 2005) Accessed March 10, 2007.

E L Grinols and D B Mustard 'Measuring industry externalities: The curious case of casinos and crime' Paper posted on the website of the National Coalition Against Legalized Gambling (http://www.ncalg. org/, 2001). Accessed March 10, 2007. [This is referred to as GM 2001 in the paper.]

E L Grinols and D B Mustard 'Casinos, crime, and community costs' The Review of Economics and Statistics (2006) 88(1) 28-45. [This is referred to as GM 2006 in the paper.]

E L Grinols and D B Mustard 'Correctly critiquing casino-crime causality' Econ Journal Watch (2008a) 5(1) 21-31. Online at http://www.econjournalwatch.org.

E L Grinols and D B Mustard 'Connecting casinos and crime: More corrections of Walker' Econ Journal Watch (2008b) 5(2) 156-162. Online at http://www.econjournalwatch.org.

E L Grinols, D B Mustard and C H Dilley 'Casinos and crime’ (University of Illinois working paper, 1999). Copy available from the author. (June) [This is referred to as GM 1999 in the paper.]

E L Grinols and J S Rose 'Another voice: Laudatory report misstates conclusions on gambling' Buffalo News (2007) (March 13).

J J Heckman 'Sample selection bias as a specification error' Econometrica (1979) 47(1) 364-369.

Las Vegas Convention and Visitors Authority 2006 Las Vegas Year-to-Date Executive Summary (Online at http://www.lvcva.com/press/statistics-facts/, 2006) Accessed March 10, 2007.

J R Lott and J Whitley 'Measurement error in county-level UCR data' Journal of Quantitative Criminology (2003) 19(2) 185-198.

M D Maltz 'Bridging gaps in police crime data' (Bureau of Justice Statistics, 1999).

M D Maltz and J Targonski 'A note on the use of county-level UCR data' Journal of Quantiative Criminology (2002) 18(3) 294-318.

M D Maltz and J Targonski 'Measurement and other errors in county-level UCR data: A reply to Lott and Whitley' Journal of Quantitative Criminology (2003) 19(2) 199-206.

T Miller, M Cohen and B Wiersema 'Victim costs \& consequences: A new look' (U.S. Department of Justice, 1996).

W J Miller and M D Schwartz 'Casino gambling and street crime' Annals of the American Academy of Political \& Social Science (1998) 556 124-137.

J J Monahan 'Economists fuel casino debate: Charges of bias leveled as barbs are traded' Worcester Telegram \& Gazette (28 October) (Online at http://www.telegram.com, 2007).

R Morin 'Casinos and crime: The luck runs out' Washington Post (11 May) (Online at http://www. washington post.com, 2006).

E A Morse and E P Goss Governing Fortune: Casino Gambling in America (University of Michigan Press, 2007).

G Nettler Explaining Crime (New York, NY, McGraw-Hill, 3rd edn, 1984).

PolicyAnalytics 'A benefit-cost analysis of Indiana's riverboat casinos for FY 2005: A report to the Indiana Legislative Council and the Indiana Gaming Commission' (17 January) (2006).

W S Reese 'Casinos, hotels, and crime' (West Virginia University working paper, 2008) Available from the author (July).

B G Stitt, M Nichols and D Giacopassi 'Does the presence of casinos increase crime? An examination of casino and control communities' Crime \& Delinquency (2003) 49(2) 253-284.

P Stokowski 'Crime patterns and gaming development in rural Colorado' Journal of Travel Research (1996) 34 63-69.

E Vitagliano 'Casinos and crime: A sour bet' American Family Association Journal (August) (Online at http://afajournal.org/2006/august/0806casinos.html, 2006).

B Yarbrough 'Casinos increase crime' Hesperia Star (6 June) (Online at http://www.hesperiastar.com/ story.php?id=1570_0_1_0_C, 2006).

D M Walker The Economics of Casino Gambling (New York, NY, Springer, 2007).

D M Walker 'Do casinos really cause crime?' Econ Journal Watch (2008a) 5(1) 4-20. Online at http:// www.econjournalwatch.org. 
D M Walker 'The diluted economics of casinos and crime: A rejoinder to Grinols and Mustard's reply' Econ Journal Watch (2008b) 5(2) 148-155. Online at http://www.econjournalwatch.org.

D M Walker 'Final comments on the casinos and crime' Econ Journal Watch (2008c) exchange. College of Charleston working paper. Available from the author.

D M Walker and J D Jackson ‘Do U.S. gambling industries cannibalize each other?' Public Finance Review (2008) 36(3) 308-333.

\section{APPENDIX}

In earlier drafts of the paper GM included the sixth and seventh year lags. The results were "typically positive and statistically significant" (GM 2006, p. 40). What they do not report is that, for most types of crime (except larceny and auto theft), the rates actually begin to level off or even fall after the fifth year. ${ }^{36}$ However, the number of non-Nevada counties on which these estimates were based is even smaller than lag 5: 12 in the sixth year and only seven in the seventh year. ${ }^{37}$

The violent crime and property crime figures from the published GM 2006 paper are reproduced below. These figures are followed by their respective figures from the $1999 \mathrm{GM}$ draft paper. A comparison of the figures makes one wonder whether the high crime rates found in the fifth year would continue if GM included data beyond $1996 .{ }^{38}$ 
Figure 4.-Casino Effects-Violent Crime

1. Aggravated Assault

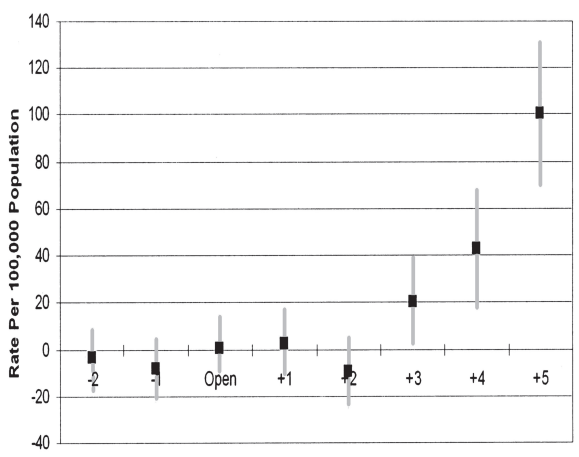

Years Relative to Casino Opening

3. Robbery

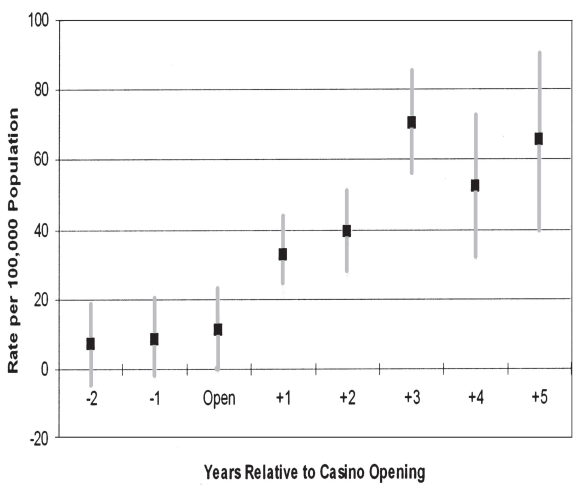

2. Rape

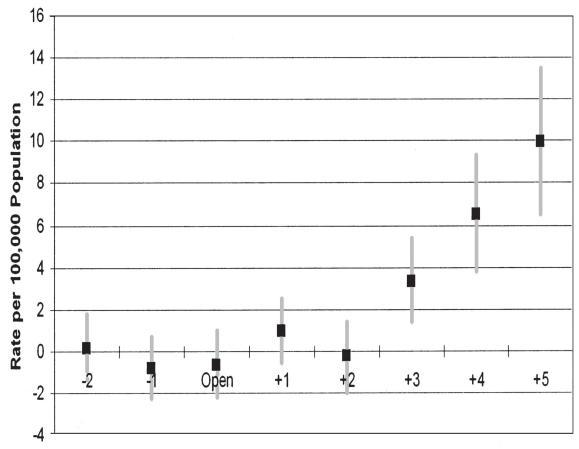

Years Relative to Casino Opening

4. Murder

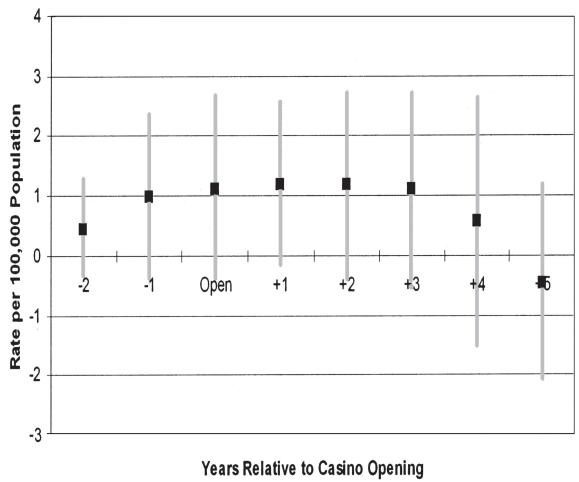

Violent crime (GM 2006 paper, p. 38, Figure 4). Estimated crime rates: 2 lead periods and 5 lag periods. This figure shows the violent crime rates (except murder) in casino counties are the highest five years after the first casino opens. One might infer that the rates continue to rise after year five. 
EVALUATING CRIME ATTRIBUTABLE TO CASINOS IN THE U.S.
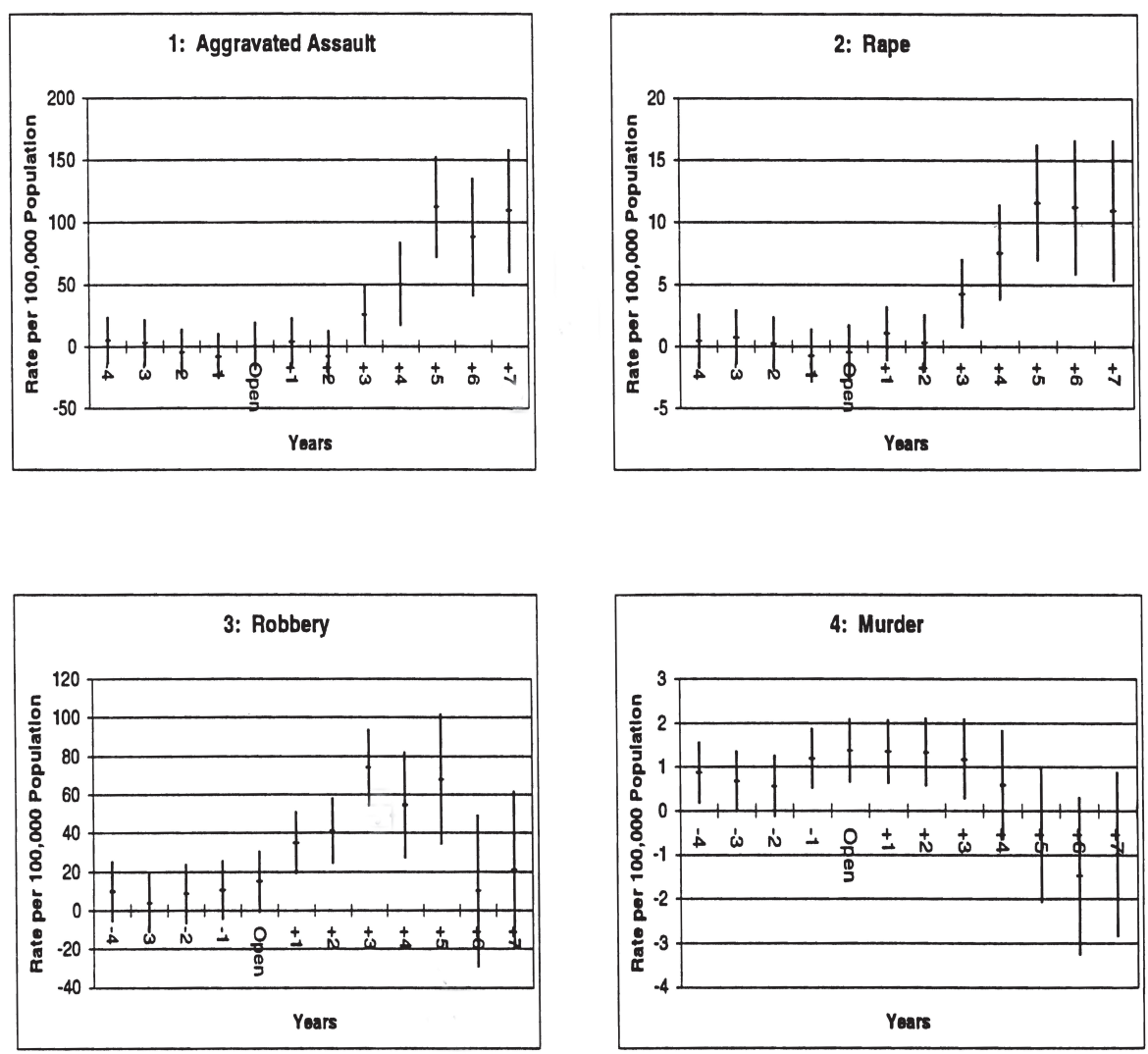

\section{Figụre 7: Violent Crime}

Violent crime (GM 1999 paper, p. 20, Figure 7). Estimated crime rates: 4 lead periods and 7 lag periods. The violent crime figure from an earlier draft shows that the crime rates level off or even fall after the fifth year following the first casino opening. 
FiguRe 5-CAsino EFFects-Property Crime

1. Larceny

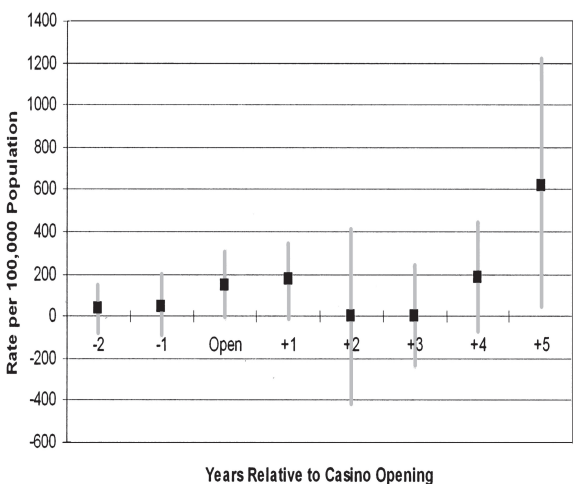

2. Burglary

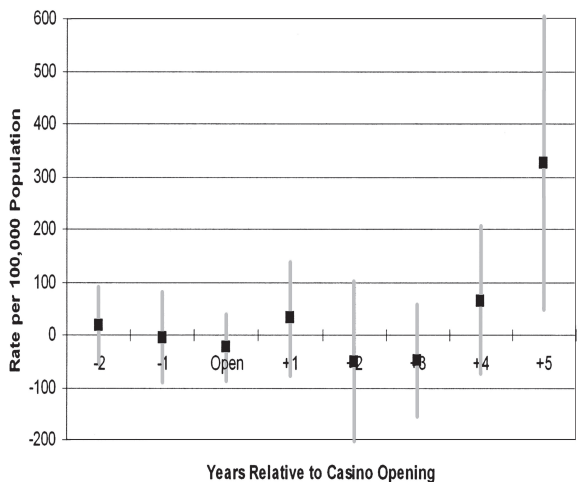

3. Auto Theft

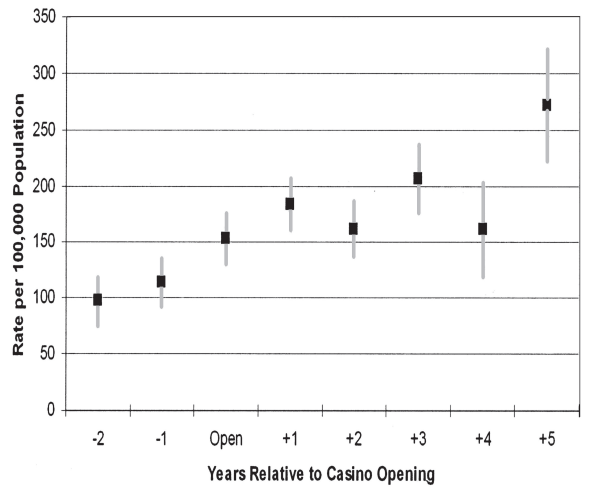

Property crime (GM 2006 paper, p. 39, Figure 5). Estimated crime rates: 2 lead periods and 5 lag periods. This figure shows that for property crimes, the crime rate is highest in the fifth year following casino opening. 
EVALUATING CRIME ATTRIBUTABLE TO CASINOS IN THE U.S.
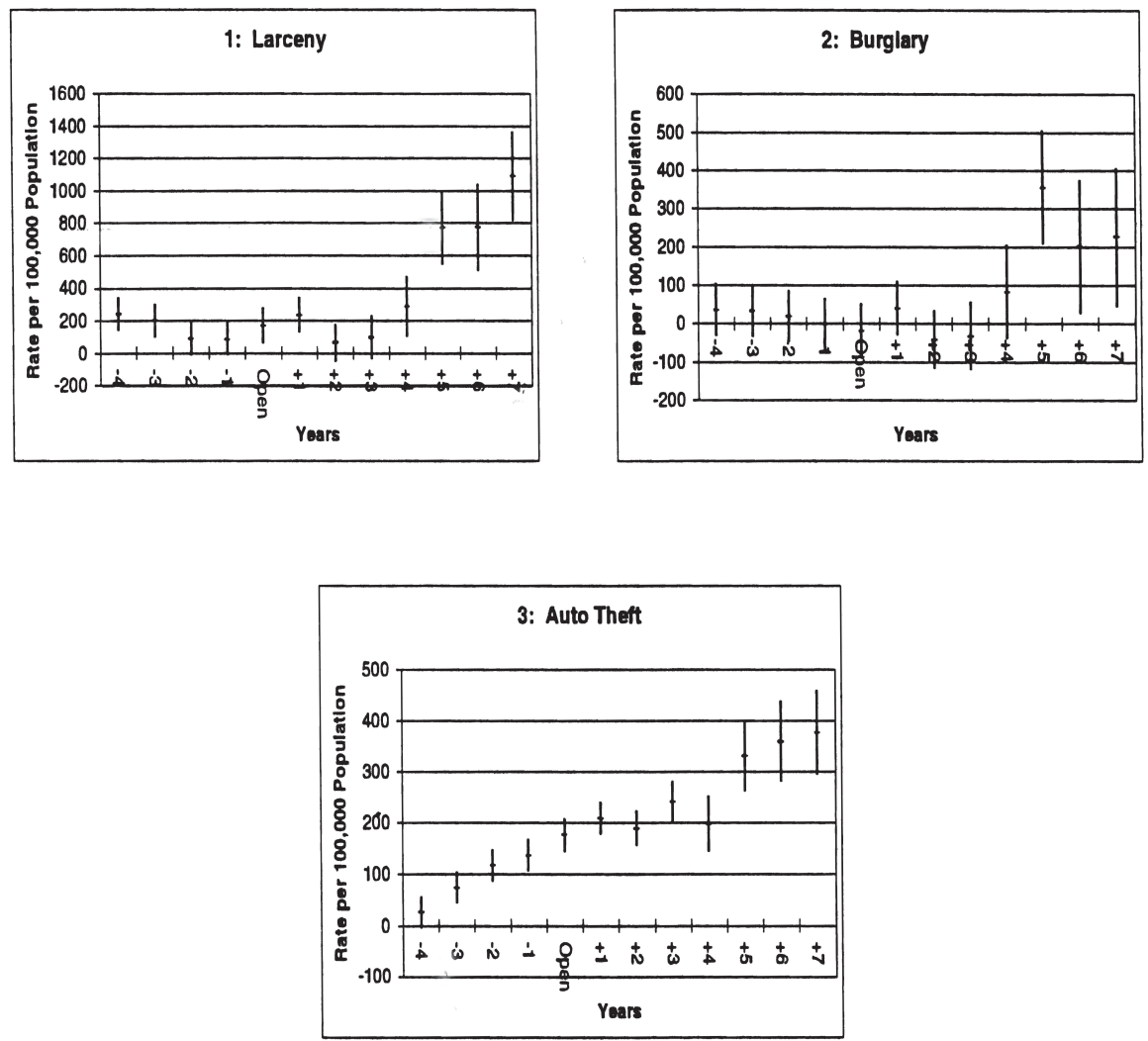

Figure 8: Property Crime

Property crime (GM 1999, p. 22, Figure 8). Estimated crime rates: 4 lead periods and

7 lag periods. The rates for larceny and auto theft continue to increase, but the burglary rate falls, after the fifth year following the first casino opening. 